\title{
Demonstrationen von Hautkrankheiten anhand von Diapositiven
}

R. ScHUPPLI, Basel: Ausgewählte Krankheitsfälle

A. BASSET, Straßburg: Lepra

H. J. HeITE, Freiburg: Morbus Behçet, insbesondere die Stichkanalentzündung nd ihre Histologie.

\section{Wissensehaftliche Ausstellungen}

A. Sarkoidose

Private Kuranstalten Höchenschwand im Schwarzwald (Prof. K. WURM)

Universitäts-Hautklinik Helsinki (Prof. T. PUtKones)

I. Universitäts-Hantklinik Wien (Prof. J. TAPPEINER)

Medizinische Universitäts-Klinik Freiburg (Prof. L. HetLMeyer)

Universitäts-Hautklinik Freiburg (Prof, K. W. KALKOFF).

B. Vitalhistologie

F. Ehring u. J. Schumann, Heilstätte Hornheide-Münster

L. ILLIG, Universitäts-Hautklinik Freiburg.

C. Physikalische Allergie

L. ILLIG, Universitäts-Hautklinik Freiburg.

D. Dokumentation und Statistik bösartiger Hauttumoren

H. J. HнIте, Universitäts-Hautklinik Freiburg.

E. Spitz-Tumor (sogenanntes juveniles Melanom)

H. J. HerTe, Universitäts-Hautklinik Freiburg. 